DOI 10.37882/2223-2982.2020.12-2.27

\title{
ГЕОМЕТРИЧЕСКИЕ ЗАДАЧИ НА ПОСТРОЕНИЕ В ЭЛЕКТРОННОЙ ОБРАЗОВАТЕЛЬНОЙ СРЕДЕ КАК СРЕДСТВО РАЗВИТИЯ ПОНЯТИЙНЫХ ПСИХИЧЕСКИХ СТРУКТУР ОБУЧАЮЩИХСЯ: СОцИОКУЛЬТУРНЫЙ ПОДХОД
}

\section{GEOMETRIC TASKS FOR BUILDING IN AN ELECTRONIC EDUCATIONAL ENVIRONMENT AS A MEANS OF DEVELOPING STUDENTS ' CONCEPTUAL MENTAL STRUCTURES: A SOCIO-CULTURAL APPROACH}

N. Podaeva

P. Agafonov

Summary: In the context of the socio-cultural approach, the problem of developing students ' cognitive mental structures in the process of learning geometry based on a model whose components are presented in the form of blocks is studied. The purpose of the article is to describe the technology of forming students ' generalized ability to solve geometric construction problems in an electronic educational environment focused on the development of conceptual mental structures. The key factor is the transition from subject-oriented teaching of mathematics to instrumental and value-oriented, which corresponds to the transformation of the content area of mathematical knowledge into procedural and contextual. Building tasks, being a fundamentally new form of activity for a teenager, allow you to transform declarative knowledge that provides an understanding of the educational material into procedural knowledge that ensures the assimilation and application of geometric concepts, as well as value-based knowledge that ensures the transfer of value positions and creates conditions for the formation of the value-semantic sphere of the student's personality.

The analysis of statistical data confirmed the hypothesis: the student's mastery of the generalized ability to solve problems on geometric constructions in the situation of socio-cultural-oriented learning has a positive effect on the development of his conceptual mental structures.

Keywords: tool-oriented, subject-oriented, value-oriented learning, content, process and contextual areas of knowledge, semantic structures, value-semantic sphere of the individual, understanding, assimilation, application.

\section{ВвеАение}

A ктуальность исследования определяется тем, что в психодидактической парадигме содержание учебного предмета должно быть проекцией не столько нормативного научного знания, сколько основ-
Подаева Наталия Георгиевна

д.n.н., профессор, Елецкий государственный университет им. И.А. Бунина, podaeva@mail.ru

Агафонов Павел Александрович Учитель, ГБОУ СОШ № 2070 г. Москвы, agafon85@rambler.ru

Аннотация: В контексте социокультурного подхода исследуется проблема развития понятийных психических структур обучающихся в процессе обучения геометрии на основе модели, компоненты которой представлены В виде блоков. Цель представить характеристику технологии формирования у школьников обобщенного умения по решению геометрических задач на построение в электронной образовательной среде, ориентированной на развитие понятийных психических структур. Ключевым фактором выступает переход от предметно-ориентированного обучения математике к инструментально- и ценностно-ориентированному, что соответствует трансформации содержательной области математического знания в процессуальную и контекстуальную. Задачи на построение, являясь для подростка принципиально новой формой деятельности, позволяют преобразовать декларативные знания, обеспечивающие понимание учебного материала, в процедурные, обеспечивающие усвоение и применение геометрических понятий, а также в ценностные, обеспечивающие переживание ценностных позиций и создающие условия для формирования ценностно-смысловой сферы личности обучающегося.

Проведенный анализ статистических данных подтвердил гипотезу: овладение школьником обобщенным умением по решению задач на геометрические построения в ситуации социокультурно-ориентированного обучения положительно влияет на развитие его понятийных психических структур.

Ключевые слова: инструментально-ориентированное, предметно-ориентированное, ценностно-ориентированное обучение, содержательная, процессуальная и контекстуальная области знания, семантические структуры, ценностно-смысловая сфера личности, понимание, усвоение, применение.

ных закономерностей интеллектуального развития личности. В свою очередь, в русле социокультурного подхода социализация рассматривается как процесс освоения субъектом структурных элементов деятельности, в том числе таких ее форм, как понятийная мыслительная деятельность. В этой связи развитие понятийных психи- 
ческих структур, обеспечивающие освоение способов понимания, применения научных понятий, ценностное признание, осмысление знаково-символических конструкций дисциплинарного знания, следует рассматривать как основной результат обучения геометрии.

В исследовании утверждается мысль, что в современном образовании признание социокультурной функции обучения предполагает необходимость развития понятийных психических структур обучающихся как интегральных когнитивных структур, которые выступают в качестве носителя понятийного знания, характеризуются включенностью разных способов кодирования информации, представленностью когнитивных схем разной степени обобщенности, иерархической организацией семантических признаков в содержании понятия и наличием систем связей отдельного понятия с некоторым множеством других понятий.

Было установлено, что наиболее адекватной моделью развития понятийных психических структур при обучении геометрии в школе является целостная модель, компоненты которой представлены в виде блоков: 1) формирование когнитивных схем, семантических структур - рефлексивного отношения, предполагающего понимание школьником математической информации; 2) развитие индивидуальных стилей кодирования информации; 3) формирование ценностно-смысловой сферы личности.

Ключевым моментом выступает дифференциация видов обучения, областей математического знания, а также типов научных знаний (таблица 1).

Таблица 1.

Виды обучения математике

\begin{tabular}{|l|l|l|}
\hline $\begin{array}{l}\text { Предметно-ориенти- } \\
\text { рованное обучение }\end{array}$ & $\begin{array}{l}\text { Инструментально- } \\
\text { ориентированное }\end{array}$ & $\begin{array}{l}\text { Ценностно-ориенти- } \\
\text { рованное обучение }\end{array}$ \\
\hline \multicolumn{3}{|c|}{ Области математического знания } \\
\hline Содержательная & Процессуальная & Контекстуальная \\
\hline Типы научных знаний \\
\hline $\begin{array}{l}\text { Декларативный } \\
\text { (знания о том, «что») }\end{array}$ & $\begin{array}{l}\text { Процедурный } \\
\text { (знания 0 том, «как») }\end{array}$ & $\begin{array}{l}\text { Ценностный } \\
\text { (знания о том, «какой } \\
\text { и зачем») }\end{array}$ \\
\hline
\end{tabular}

Основная цель декларативных знаний - обеспечение понимания: формирование когнитивных схем, семантических структур - индивидуальной системы значений математических терминов [22].

Основная идея исследования - в процессе становления понятий должны учитываться не только и не столько декларативные знания, сколько процедурные и ценностные. С этой точки зрения речь идет о форми- рование ченностно-смысловой сферы личности как социально обусловленной направленности, в структуре которой выделяются когнитивный, эмоциональный и поведенческий компоненты. Ценностные представления составляют когнитивный компонент. Эмоциональный компонент представлен ценностными отношениями, обеспечивающими включенность ценностных представлений в личностно признанную систему ценностей. Данное принятие ценности будет способствовать формированию ценностных ориентаций и личностных смыслов, которые составляют поведенческий компонент, представленный реализацией принятых обучающимся ценностей в поведении и деятельности. В этой связи задачи на построение являются для подростка принципиально формой деятельности, которая позволяет формировать процедурные и ценностные знания.

Анализ различных подходов к определению понятийных структур убедил авторов обратиться к наиболее равновесной концепции (Л.М. Веккер [5], М.А. Холодная [23]), согласно которой понятийная мысль есть результат взаимоперевода модальностей опыта: словесно-речевой, визуально-пространственной, предметно-практической, сенсорно-эмоциональной. При этом в качестве основных этапов процесса формирования «субъективного образа содержания понятия» выделяются: мотивировка, категоризация, обогащение, перенос и свертывание $([23$, с. 93]).

С учетом исследованных особенностей школьной методики обучения математике [1], [2] было установлено, что традиционно при введении новых понятий много времени отводится декларативным знаниям - математическому объекту, работе с определением. В то же время понятийная мыслительная деятельность, непосредственно связанная с освоением мыслительных действий и операций, должна способствовать трансформации декларативных знаний в процедурные и ценностные. В процессе обучения задачам на построения происходит освоение обучающимися графических схем, способности подбирать их к существующим геометрическим объектам, развитие сенсорных систем [1].

Было установлено, что до сих пор нет общего представления о феномене «навык геометрического построения». Традиционно его принято относить к учебным навыкам, основу которых составляют предметные действия. По нашему мнению, в основе данного навыка лежат реальные, формальные и целостные операции, интериоризированные и недоступные для объективации. Очевидно, что необходимо единое научно обоснованное представление о том, какова роль задач на построение в формировании способности подростка устанавливать максимальное количество символьных связей в окружающем мире, в формировании его понятийных 
психических структур.

Не перечисляя известные барьеры, с которыми учитель в школе сталкивается при обучении конструктивным задачам, отметим лишь, что многие из них объясняются отсутствием ценностных отношений, ченностных ориентаций и личностных смыслов.

\section{Обзор ^итературы}

В результате анализа развития взглядов на социокультурно-ориентированное обучение выявлен ряд тенденций: процесс обучения рассматривается как социокультурное явление (П.А. Сорокин [20]); важным социальным фактором выступают социальные ценности (П.Г. Щедровицкий [25]); сущность социокультурной функции обучения рассматривается как регулирование отношений между индивидом и общественным опытом через определенные механизмы, включающие ценностные ориентации, ценностный подход (И.Е. Шершов [24]).

Анализируя концепции и идеи, предполагающие свое понимание усвоения общественного знания отдельным человеком, отметим концепцию социокультурного обучения математике (Н.Г. Подаева, М.В. Подаев [13], [14], [15], [16], [28]), в контексте которой утверждается мысль, что в современном образовании признание социокультурной функции обучения предполагает существование социокультурной технологии, направленной на передачу социально и личностно-значимого опыта деятельности, представленного в виде знаний, умений, навыков и культурных базовых способностей

Важнейшие свойства понятийного мышления глубоко проработаны в науке (Л.М. Веккер [1], Л.С. Выготский [3], П.Я. Гальперин [4], В.В. Давыдов [8], Е.Н. КабановаМеллер [10], Ж. Пиаже [12], С.Л. Рубинштейн [17], М.А. Холодная [23] и др.) Процесс усвоения школьниками математических понятий исследовался в работах Я.И. Груденова [6], В.А. Гусева [7], В.А. Далингера [9], Н.В. Метельского [11], А. Пуанкаре [29], Г.И. Саранцева [18], 3.И. Слепкань [19], А.А. Устиловской [21], И.С. Якиманской [26] и др. В исследованиях Н.Г. Подаевой, М.В. Подаева, П.А. Агафонова [14], [15], [16] были выделены компоненты целостной психической структуры, обеспечивающей в ситуации обучения геометрии формирование деятельности по освоению геометрических понятий.

Проблеме внедрения автоматизации в образовательную среду посвящены работы Jari Kaivooja [39]. Проблеме цифровизации обучения и трансформации роли преподавателя в образовании при условии полной цифровизации процесса обучения посвящены исследования [30], [31], [32], [33], [34], [35], [36], [37], [38].
Вопросам использования в образовательном процессе цифровых сред посвящены исследования И.Н. Голицыной [27]. Модульные цифровые образовательные среды исследованы в работах [40], [41]. МООС и дистанционному образованию посвящены работы [42], [43], [44], [45], [46]. 47].

\section{Методы}

Целью экспериментального обучения являлось развитие понятийных психических структур обучающихся 8-9-х классов через освоение ими обобщенных умений по решению задач на геометрические построения в рамках факультатива «Конструктивная геометрия на евклидовой плоскости».

Отметим, что в рамках экспериментальной методики действия, составляющие содержание умения по решению конструктивных задач, выступали в качестве специального предмета усвоения. В качестве единиц мыслительного процесса выступали целостные операции, которые фиксируются в сознании в виде образов, включают в себя реальные и формальные операции, что обеспечивает единство плоскости содержания (плоскости геометрического объекта) и плоскости знаковой формы. Покажем это на примере отдельного занятия в рамках авторского элективного курса в 9 классе. Тема занятия: «Метод пересечений для решения задач на построения циркулем и линейкой. Окружность Аполлония».

Вначале раскрывается сущность метода пересечений: задачу сводят к построению одной точки $X$ (основного элемента построений), которая удовлетворяет каким-либо двум условиям $a_{1}$ и $a_{2^{\prime}}$ вытекающим из постановки задачи.

Пусть $F_{1}$ - множество (геометрическое место) точек, удовлетворяющих условию $a_{1}$, а $F_{2}$ - множество (геометрическое место) точек, удовлетворяющих условию $a_{2}$. Тогда искомой точкой $X$ будет любая точка множества $F_{1} \cap F_{2}$.

С использованием ресурса динамической системы GeoGebra рассматриваются образы (геометрические места точек) $F_{1}$ и $F_{2}$.

Далее рассматриваем опорную задачу: «Дан отрезок $A B$ и точка $C$, принадлежащая прямой $A B$. Построить геометрическое место точек $F=\{X \mid A X: X B=A C: C B\}$ (окружность Аполлония)».

Формально-дедуктивные рассуждения предваряются математическим экспериментом в системе GeoGebra. Проанализировав условие, на этапе анализа делается предположение, что задача решена, то есть X - одна из точек искомого множества $\boldsymbol{F}$. Из этого вытекает, что XC 
- биссектриса угла AXB. Рассматривается точка $\boldsymbol{D}$ на прямой $A B$, такая, что прямая XD перпендикулярна XC. Делается вывод, что XD - биссектриса угла, внешнего для AXB. Следовательно, $\angle \mathrm{CXD}=\mathbf{9 0 ^ { \circ }}$ и точка $\mathrm{X}$ лежит на окружности с диаметром CD. Затем проводятся обратные рассуждения и доказывается, что любая точка окружности с диаметром CD принадлежит множеству F. Делается вывод о том, что множество $F$ и есть окружность, которая называется окружностью Аполлония. Далее проводятся рассуждения методом восходящего анализа: для того чтобы построить окружность Аполлония, достаточно найти точку $\boldsymbol{D}$ и провести окружность с диаметром $C D$. Учащиеся задаются вопросом: как построить точку $D$ ? Ответ дает теорема Фалеса (рис.1).

Данная методика позволяет в результате изучения окружности Аполлония как образа, фиксирующего математический объект, его связи и отношения, сформировать понятие «окружность Аполлония», освоение которого в результате простого заучивания невозможно.

\section{Результаты}

Экспериментальная апробация проводилась в течение 2017-2020 гг. в ГБОУ СОШ №2070 г. Москвы КШО и ГБОУ СОШ №2070 г. Москвы БШО. Участниками эксперимента были определены предпрофильные классы (физико-математического профиля): ГБОУ СОШ №2070 г. Москвы КШО (Коммунарское Школьное Отделение) 8 «а» и 9 «а» классы; ГБОУ СОШ №2070 г. Москвы БШО (Бунинское Школьное Отделение) - 8 «в» и 9 «в» классы. Обучение в рамках факультатива «Конструктивная геометрия на евклидовой плоскости» выступало дополни- тельной необязательной формой предметной подготовки и являлось значимым механизмом, поддерживающим основные занятия по геометрии.

При проведении оценки результатов экспериментального исследования мы исходили из следующих независимых характеристик для формируемых действий: системность, реслексивность, обратимость, гибкость, форма действия, степень обобщения и категоризации, мера развернутости, мера переноса, мера освоения и обогащения, ценностно-смысловая сфера, мера свернутости.

Для сопоставительного анализа оценки сформированности уровня обобщенного способа решения геометрических задач на построение в электронной образовательной среде и оценки уровня развития понятийных психических структур обучающихся была использована таблица 2.

В ходе проведения эксперимента была подтверждена гипотеза о значимом влиянии уровня математической подготовки с использованием апробируемой методики.

\section{Зак^ючение}

В ходе исследования были получены следующие результаты: уровень обученности геометрии динамически развивается, а именно, растет такой показатель интеллектуального развития личности, как понятийные психические структуры, если социокультурно-ориентированное обучение в рамках факультатива «Конструктивная геометрия на евклидовой плоскости» выступает дополнительной необязательной формой предметной

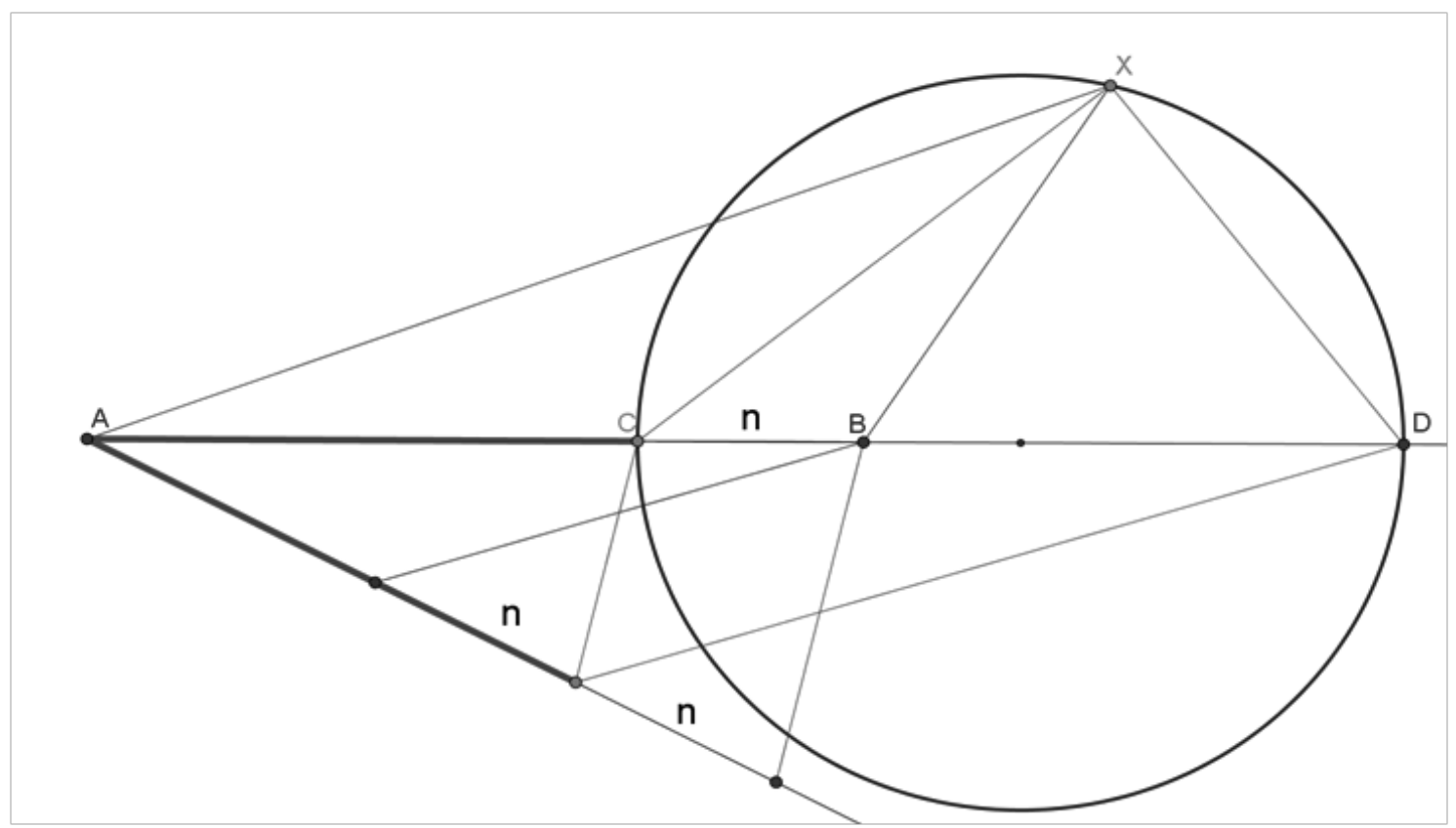

Рис. 1. 


\begin{tabular}{|c|c|c|c|}
\hline № & Уровень & Психодидактические закономерности & Характеристика критерия развития \\
\hline 1. & Понимание & Осознание, обобщение, осмысление & $\begin{array}{l}\text { Рефлексивный критерий: знания характеризуются как декларативные; умение } \\
\text { по решению задач носит обобщенный характер, но не характеризуется быстротой } \\
\text { выполнения действий; построения обосновываются результатами анализа, но сла- } \\
\text { бо аргументированы. } \\
\text { Когнитивный критерий: ценностные преставления восприняты, но не приняты } \\
\text { личностью обучающегося. } \\
\text { Эмоциональный критерий: ценностное отношение не сформировано. } \\
\text { Поведенческий критерий: ценностные ориентации ограничены; личностные } \\
\text { смыслы не сформированы; преобладают широкие познавательные мотивы; вну- } \\
\text { тренние мотивы подчинены внешним. }\end{array}$ \\
\hline 2. & Усвоение & $\begin{array}{l}\text { Запоминание, систематизация, профилактика } \\
\text { забывания }\end{array}$ & $\begin{array}{l}\text { Рефлексивный критерий: знания определяются как декларативные, мыслитель- } \\
\text { ное умение автоматизировано; школьник аргументирует свою точку зрения. } \\
\text { Когнитивный критерий: ценностные преставления приняты личностью обучаю- } \\
\text { щегося. } \\
\text { Эмоциональный критерий: ценностное отношение находится на стадии форми- } \\
\text { рования. } \\
\text { Поведенческий критерий: преобразование широких познавательных мотивов в } \\
\text { учебно-познавательные; внутренние и внешние мотивы сбалансированы. }\end{array}$ \\
\hline 3. & $\begin{array}{c}\text { Эмоцио- } \\
\text { нально- } \\
\text { оценочный } \\
\text { уровень }\end{array}$ & Переживание ценностных позиций & $\begin{array}{l}\text { Рефлексивный критерий: знания учащихся характеризуются как ценностные, } \\
\text { выражаются в виде оценочных суждений; происходит опора на сенсорно-эмоци-- } \\
\text { нальный способ кодирования информации. } \\
\text { Когнитивный критерий: ценностные преставления включены в личностно при- } \\
\text { знанную систему ценностей обучающегося. } \\
\text { Эмоциональный критерий: ценностные отношения сформированы. } \\
\text { Поведенческий критерий: ценностные ориентации и личностные смыслы выра- } \\
\text { жены в реализации принятых обучающимся ценностей в поведении и деятельно- } \\
\text { сти; наблюдается динамическое изменение личности обучающегося в соответствии } \\
\text { спринятой целью; внутренние мотивы носят доминирующий характер. }\end{array}$ \\
\hline 4. & Применение & $\begin{array}{l}\text { Формирование умений, стандартное приме- } \\
\text { нение, творческое применение }\end{array}$ & $\begin{array}{l}\text { Рефлексивный критерий: знания определяются как процедурные и ценностные; } \\
\text { широта переноса приемов указывает на обобщенный характер сформированного } \\
\text { умения; мыслительное умение не автоматизировано; каждый раз умение осущест- } \\
\text { вляется при полном осознании как самой задачи, так и способов её решения. } \\
\text { Когнитивный критерий: ценностные преставления входят в систему ценностей с } \\
\text { помощью отражения в сознании. } \\
\text { Эмоциональный критерий: ценностные отношения сформированы. } \\
\text { Поведенческий критерий: принятые ценности реализуются в поведении и дея- } \\
\text { тельности; обеспечено усвоение школьниками системы целостных операций, ре- } \\
\text { зультатом освоения которых является геометрическое понятие. }\end{array}$ \\
\hline
\end{tabular}

подготовки и является значимым механизмом, поддерживающим основные занятия по данному предмету, причем осуществляется методическое сопровождение данного процесса на основе соблюдения таких положений, как:

- содержание дополнительного обучения геометрии фундировано социокультурной концепцией математического образования;

- процесс развития понятийных психических структур опосредован овладением школьником обобщенным умением решения геометрических задач на построения;

- специфика процесса обучения геометрии основана на целостной модели, компоненты которой представлены в виде блоков: 1) формирование когнитивных схем, семантических структур - рефлексивного отношения, предполагающего понимание школьником математической информации; 2) развитие индивидуальных стилей кодирования информации; 3) формирование ценностно-смысловой сферы личности обучающегося. 


\section{ЛИТЕРАТУРА}

1. Веккер Л.М. Психические процессы. Мышление и интеллект. Т.2. Л.: Изд-во ЛГУ, 1976. С. 75.

2. Владимирцева С.А. Теория и методика обучения математике: Общая методика. Изд. 2. Барнаул: Издательство БГПу, 2007. 189 с.

3. Выготский Л.С. Собрание сочинений: В 6 т. Т. 2: Мышление и речь. - [Текст] / Л.С. Выготский. - М.: Педагогика, 1982.

4. Гальперин П.Я. Методы обучения и умственное развитие. - М. : Просвещение, 1985. - 102 с.

5. Гельфман Э.Г. Психодидактика школьного учебника : учебное пособие для вузов / Э.Г. Гельфман, М.А. Холодная. — 2-е изд., испр. и доп. — Москва : Издательство Юрайт, 2019. — 328 c. — (Образовательный процесс). — ISBN 978-5-534-06481-0. — Текс: электронный // ЭБС Юрайт [сайт]. — URL: https://urait.ru/bcode/441935 (дата обращения: 12.03.2020).

6. Груденов Я.И. Психолого-дидактические основы методики обучения математике / Я.И. Груденов. М.: Педагогика, 1987. 159с.

7. Гусев В.А. Психолого-педагогические основы обучения математике. М.: 000 «Издательство «Вербум-М», 000 «Издательский центр «Академия», 2003.

8. Давыдов В.В. Психологическая теория учебной деятельности и методов начального обучения, основанных на содержательном обобщении. Томск: Издательство «Пеленг», 1992.

9. Далингер В.А. Методика обучения учащихся доказательству математических предложений. М.: Просвещение, 2006.

10. Кабанова-Меллер Е.Н. Психология формирования знаний и навыков школьников. М.: Изд-во АПН РСФСР, 1962.

11. Метельский Н.В. Дидактика математики. Минск, 1982.

12. Пиаже Ж. Избранные психологические труды. Психология интеллекта / Пер. с франц. В.А Лекторского и др. М.: Просвещение, 1969.

13. Подаева Н.Г., Подаев М.В., Агафонов П.А. Формирование понятий в процессе обучения геометрии школьников в электронной образовательной среде // Научно-методический электронный журнал «Концепт». - 2019. - № 6 (июнь). - URL: http://e-koncept.ru/2019/191040.htm. (BAK) D0I 10.24411/2304120X-2019-11040

14. Подаева Н.Г. Социокультурная концепция математического образования Елец: ЕГУ им. И.А. Бунина, 2012. - 205 с.

15. Подаева Н.Г., Подаев М.В. Обновление содержания школьного математического образования: социокультурный подход СПб.: Издательство «Лань», 2014. -224 c.

16. Подаева Н.Г., Подаев М.В. Технология социокультурно-ориентированного обучения геометрии в общеобразовательной школе. Елец: ЕГУ им. И.А. Бунина, 2016. -187 C.

17. Рубинштейн С.Л. Основы общей психологии. СПб.: Питер Ком, 1999.

18. Саранцев Г.И. Цели обучения математике в средней школе в современных условиях // Математика в школе. 1999, №6. С. 36-41.

19. Слепкань 3.И. Психолого-педагогические основы обучения математике: Метод. пособие. К.: Рад. школа, 1983.

20. Сорокин П.А. Человек, цивилизация, общество. - М.: Просвещение, 1992. - 591 с.

21. Устиловская А.А. Психологические механизмы преодоления знаковой натурализации идеального содержания геометрических понятий: дисс. ....канд. псих. наук. - М., 2008. - 160 с.

22. Ушакова Т.Н. Функциональные структуры второй сигнальной системы. - М.: Наука, 1970. - с

23. Холодная М.А. Психология интеллекта. Парадоксы исследования [Текст] / М.А. Холодная. - СПб.: Питер, 2002. 264 с.

24. Шершов И.Е. Динамика культуры. - Минск: БГУ, 1980. - 183 с.

25. Щедровицкий Г.П. Избранные труды [Текст] / Г.П. Щедровицкий — М.: Шк.Культ.Полит., 1995. — 800 c.

26. Якиманская И.С. Психологические основы математического образования: учеб. пособие для студ. вузов - М.: Академия, 2004-319 с.

27. Голицына И.Н. Технология Образование 3.0 в современном учебном процессе // Образовательные технологии и общество. 2014.Т. 17. № 3.

28. Podaeva N.G., Podaev M.V., Agafonov P.A. The social and cultural approach to forming geometric concepts among schoolchildren // Amazonia Investiga, Vol. 8 , Num. 20. 2019. http://www.udla.edu.co/revistas/index.php/amazonia-investiga/article/view/1466 (WoS)

29. Poincaré H. An Essay On The Psychology Of Invention In The Mathematical Field / H. Poincaré, J. Hadamard. - Princeton Univ Press (1949).

30. Куприяновский В.П., Синягов С.А., Намиот Д.Е., Добрынин А.П., Черных К.Ю. Информационные технологии в системе университетов, науки и инновации в цифровой экономике на примере Великобритании // International Journal of Open Information Technologies. 2016. Т. 4. № 4

31. Намиот Д.Е., Куприяновский В.П., Самородов А.В., Карасев О.И., Замолодчиков Д.Г., Федорова Н.О. Умные города и образование в цифровой экономике // International Journal of Open Information Technologies. 2017. T. 5. № 3.

32. Bruce D.L., Chiu M.M. Composing with new technology: Teacher reflections on learning digital video // Journal of Teacher Education. 2015. T. 66. № 3. C. 272-287. URL: http://dx.doi.org/10.1177/0022487115574291

33. Dicheva D. Dichev C., Agre G., Angelova G. Gamification in education: a systematic mapping study. Journal of Educational Technology \& Society. 2015. T. 18. No. 3. C. 75. URL: http://dx.doi.org/10.1145/3134302.3134305

34. Fenwick T., Edwards R. Exploring the impact of digital technologies on professional responsibilities and education // European Educational Research Journal. 2016. T. 15. № 1. C. 117-131. URL: http://dx.doi.org/10.1177/1474904115608387

35. Instefjord E. Appropriation of digital competence in teacher education // Nordic Journal of Digital Literacy. 2015. T. 10. № Jubileumsnummer. C. 155-171

36. Lai K.W., Hong K.S. Technology use and learning characteristics of students in higher education: Do generational differences exist? // British Journal of Educational Technology. 2015. T. 46. № 4. C. 725-738. URL: https://doi.org/10.1111/ bjet.12161 
37. Nielsen W., Miller K.A., Hoban G. Science teachers' response to the digital education revolution // Journal of Science Education and Technology. 2015. T. 24. № 4. C. 417-431. URL:https://doi.org/10.1007/s10956-014-9527-3

38. Tømte C., Enochsson A.B., Buskqvist U., Kårstein A. Educating online student teachers to master professional digital competence: The TPACK-framework goes online // Computers \& Education. 2015. T. 84. C. 26-35. URL: https://doi.org/10.1016/j.compedu.2015.01.005

39. Kaivo-oja J., Roth S. The Technological Future of Work and Robotics. 2015. URL: http://hdl.handle.net/10419/118693

40. Watson W.R., Watson S.L., Reigeluth C. M. Education 3.0: Breaking the mold with technology // Interactive Learning Environments. 2015. T. 23. № 3. C. 332-343. URL: https://doi.org/10.1080/10494820. 2013.764322

41. Wilcox C. The role of automation in undergraduate computer science education // Proceedings of the 46th ACM Technical Symposium on Computer Science Education. ACM, 2015. C. 90-95. URL: https://doi.org/10.1145/2676723.2677226

42. Куприяновский В.П., Синягов С.А., Намиот Д.Е., Добрынин А.П., Черных К.Ю. Информационные технологии в системе университетов, науки и инновации в цифровой экономике на примере Великобритании // International Journal of Open Information Technologies. 2016. Т. 4. № 4

43. Лебедева М.Б. Массовые открытые онлайн-курсы как тенденция развития образования // Человек и образование. 2015. № 1 (42).

44. Маковейчук К.А. Перспективы использования курсов в формате МООК в высшем образовании в России // Международный научно-исследовательский журнал. 2015. № 63. С. 66.

45. Валеева Н.Г., Руднева М.А. Массовые открытые онлайн-курсы в обучении студентов экологического факультета английскому языку для профессиональной коммуникации // Вестник Российского университета дружбы народов. Серия: Экология и безопасность жизнедеятельности. 2016. № 3

46. Uribe S.N., Vaughan M. Facilitating student learning in distance education: a case study on the development and implementation of a multifaceted feedback system // Distance Education. 2017. T. 38. № 3. C. 288-301. URL: https://doi.org/10.1207/s15389286ajde1903_2

47. Классов А.Б., Классова О.В. Использование системы дистанционного обучения в учебном процессе // Научный альманах. 2016. № 3-2. С. 165-169.

(c) Подаева Наталия Георгиевна (podaeva@mail.ru), Агафонов Павел Александрович (agafon85@rambler.ru).

Журнал «Современная наука: актуальные проблемы теории и практики»



